\title{
Post-tsunami Stress: A Study of Posttraumatic Stress Disorder in Children Living in Three Severely Affected Regions in Sri Lanka
}

\author{
Frank Neuner and Elisabeth Schauer \\ University of Konstanz \\ Claudia Catani \\ Vivo \\ Martina Ruf and Thomas Elbert \\ University of Konstanz
}

\begin{abstract}
At 3 to 4 weeks after the December 2004 tsunami disaster we assessed symptoms of posttraumatic stress disorder (PTSD) in 264 children who lived in severely affected coastal communities in Manadkadu (northern coast), Kosgoda (western coast), and Galle (southern coast) in Sri Lanka. The prevalence rate of tsunami-related posttraumatic stress disorder (PTSD) (ignoring the time criterion) ranged between $14 \%$ and $39 \%$ and an additional $5 \%$ to $8 \%$ had PTSD unrelated to the tsunami. The PTSD symptoms were explained by the severity of the trauma exposure and family loss, as well as previous traumatic events. The results confirm the relevance of the individual history of traumatic events for the genesis of PTSD and indicate a high need of mental health assistance among the tsunami-affected children in Sri Lanka.
\end{abstract}

On December 26, 2004, a giant tidal wave (tsunami) caused by an underwater earthquake in the Indian Ocean caused an unprecedented natural disaster in Indonesia, Sri Lanka, Thailand, and India. In Sri Lanka, the flood reached widespread coastal regions in all directions and caused more than 30,000 casualties. Countless inhabitants of these regions had to flee from their homes to provisional refugee camps or to the homes of relatives.
Beyond the immediate medical consequences of injuries and bad hygienic conditions, natural disasters can cause lasting mental disorders for significant proportions of the survivors. Immediately after the tsunami there was a high awareness in the Sri Lankan administration and the public of potential adverse psychological effects, especially for the children living in the affected areas.

\footnotetext{
Research was supported by private donations to Vivo as well as by the German Technical Cooperation (GTZ). The authors would like to thank Silke Gotthardt and Patience Lamaro Onyut for assistance in training and data collection; Daya Somasundaram, Kohiladevy Mahendrarajah, and the teacher counselor group as well as Michael Hirth, Gerhard Huck, and Sundaram Divakalala from GTZ for the continuous professional cooperation and logistical support; Christina J. Robert for editing; and Fran Norris for invaluable comments on an earlier draft of this article.

Correspondence concerning this article should be addressed to: Frank Neuner, Department of Psychology, University of Konstanz, Box D25, 78457 Konstanz, Germany. E-mail: Frank.neuner@uni-konstanz.de.
} 
In the last decade, the knowledge about the mental health consequences of natural disasters for the affected populations has been growing rapidly. In general, research has shown that posttraumatic stress disorder (PTSD) is the most prevalent psychological disorder after disaster (see Norris et al., 2002, for a review).

Although disasters in developing countries have accounted for most of the disaster victims worldwide during the last 10 years (International Federation of Red Cross and Red Crescent Societies, 2004) only a minority of studies have been carried out in nonindustrialized regions. As one exception, the 1988 earthquake in Armenia received outstanding attention from researchers. The studies showed that high numbers of victims experienced PTSD after this event and that the short- and long-term consequences in disaster-affected communities were comparable to the effects of organized violence (Goenjian et al., 1994; Goenjian et al., 2000).

The majority of disaster studies have focused on adults, although children seem to be more vulnerable to psychological impairment after disaster (Norris et al., 2002). Studies of child victims of natural disasters in developing countries show inconsistent results. PTSD prevalence ranged between $14 \%$ and $90 \%$ among children living in different communities that were affected by Hurricane Mitch in Nicaragua (Goenjian et al., 2001) and between 26\% and 95\% among children after the 1988 earthquake in Armenia (Goenjian et al., 1995). Within these studies, the main explanation of the difference was the exposure effect, which predicted higher prevalence rates in communities that were more severely affected. This exposure effect is the most reliable predictor of PTSD in disaster studies (Norris et al., 2002).

In contrast to the studies in Armenia and Nicaragua, Scott, Knoth, Beltran-Quiones, and Gomez (2003) found no evidence for a higher rate of clinically significant psychopathology among child victims of the 1999 earthquake in Colombia in comparison to a nonexposed control group. Several methodological differences between this study and studies of Nicaragua and Armenia might account for this striking result. Whereas Goenjian and coworkers (1995, 2001) used, among others, measures of posttraumatic stress disorder to assess the psychological impact of the disaster, Scott and coworkers (2003) compared their populations by using the psychopathological scales of the Hispanic version of the Minnesota Multiphasic Personality Interview (MMPI), which does not contain a scale of posttraumatic stress. In addition, Scott and colleagues (2003) compared the populations on the basis of the group means on the different MMPI scales, a method that may hide individual outliers with clinically significant elevations of symptoms. Beyond these methodological differences, Scott and colleagues (2003) speculated that cultural features of their population including high family and community support might explain the low level of psychopathology. In addition, they assumed that the high level of violence within the Colombian society might have desensitized the children to traumatic stress. This assumption is not at all straightforward as it is unclear whether previous traumatic events decrease (through desensitization) or increase (through a general dose effect) vulnerability for psychopathology after a disaster. This question is especially relevant for populations in developing countries who experience high levels of violence. In contrast to the desensitization hypothesis, the experience of previous political violence was a significant predictor of increased PTSD symptoms among adult survivors of the 1988 earthquake in Armenia (Goenjian et al., 1994). This finding is in line with several studies supporting a general dose-effect model in the genesis of PTSD. For example, Bremner, Southwick, Johnson, Yehuda, and Charney (1993) showed that Vietnam veterans who had a previous history of childhood abuse were at higher risk for PTSD. In a study of civil war adult victims in Africa, a clear linear relationship between the number of traumatic event types and posttraumatic stress could be confirmed (Neuner et al., 2004).

The potential influence of previous traumatic exposure is also relevant for countries that were affected by the tsunami. The Aceh province in Indonesia and the northeastern region of Sri Lanka have a long history of civil war before the tsunami. In Sri Lanka, the children living in the Tamil regions have been especially severely affected by the war and already showed high levels of psychopathology before the tsunami (Elbert et al., 2006; Somasundaram, 
1993). There is evidence for a dose-effect relationship between war trauma exposure and PTSD in Tamil schoolchildren living in the war-affected areas (Catani et al., 2005).

In this context it is important to examine the influence of previous traumatic events on the psychological consequences of the tsunami. In the context of a general needs assessment of affected children immediately (3-4 weeks) after the tsunami, we examined schoolchildren living in three severely affected communities. We selected three communities that were all highly affected by the tsunami but differed with regard to the extent of previous traumatic experiences. The Tamil village Manadkadu in northern Sri Lanka was completely destroyed by the tsunami and had also been severely affected by the civil war. Wide parts of the Sinhalese communities Kosgoda in the west and Galle in the south were also destroyed by the tsunami, but these communities had no recent history of war. Beyond war events, we expected more violence in the town Galle than in the rural Kosgoda, providing additional variance in previous traumatic exposure.

Although the International Classification of Diseases (ICD-10) of the World Health Organization (2004) is the regular diagnostic manual of psychiatric disorders in Sri Lanka, we based this study on the current version of the Diagnostic and Statistical Manual of Mental Disorders, fourth edition (DSM-IV; American Psychiatric Association, 1994) to allow the comparison of the results with those of other disaster studies that have almost exclusively used the DSM. According to the DSM-IV, PTSD could not be diagnosed so soon after the tsunami. Nevertheless, the preliminary diagnosis of PTSD and the severity of posttraumatic symptoms were the outcome variables as measures of acute stress disorder were not available in this context and a preliminary PTSD diagnosis seems to be a good predictor of chronic PTSD (Meiser-Stedman, Yule, Smith, Glucksman, \& Dalgleish, 2005). We expected the highest early PTSD prevalence in Manadkadu, followed by Galle and Kosgoda. Following a general dose-effect model, we predicted a significant influence of previous traumatic events on posttraumatic stress after controlling for age, gender, as well as the subjective and objective severities of tsunami exposure.

\section{METHOD}

\section{Setting}

This study was part of an initial needs assessment for children affected by the tsunami in northeastern Sri Lanka within the framework of an ongoing psychosocial school program. The posttsunami interventions built on the network and experiences developed within 3 years of a previously established school counseling program for the treatment of war-traumatized children in the war-affected northeastern Tamil regions of Sri Lanka. The program is a subcomponent of the Basic Education Sector (BeCARE) program, a collaboration between German Technical Cooperation (GTZ), the Sri Lankan Ministry of Education, the Education Council North East, the international mental health organization Vivo, the University of Jaffna, and the Sri Lankan aid organization Shantiham. Thirty-five counselors who had been trained in basic counseling skills, mental health diagnosis, and trauma treatment in that program could be recruited for the consecutive tsunami relief program within 2 weeks after the flood. In particular, these counselors had been taught to administer a standardized interview for the assessment of PTSD in children. An additional 4-day workshop was conducted to prepare the counselors for the acute conditions after the tsunami. After a request from the National Institute of Education (NIE) in Colombo, a 1-week course in trauma, its consequences, and its diagnosis was also offered to 48 Sinhalese-speaking counselors and psychologists from southern regions. All interviews were closely supervised by five mental health experts. The whole program, including the needs assessment, was approved and supported by the Sri Lankan government and administration on different levels.

\section{Participants}

The interviews were conducted between January 15 and January 23, 2005 in three severely affected communities that were accessible at that time. The village Manadkadu in the Vadamarachchi region in northern Sri Lanka was completely destroyed by the tsunami. As 
were many communities in the northeastern provinces, Manadkadu had been severely affected by the Sri Lankan civil war. In Kosgoda (western Sri Lanka) and Galle (southern Sri Lanka) the coastal areas of the communities were destroyed by the flood.

The study population were children living in the affected areas in the age range of 8 to 14 years. In Manadkadu, we interviewed all 71 eligible children who were present at the day of interview in the two provisional refugee camps that hosted almost all of the inhabitants of the village. In Kosgoda and Galle provisional schooling was operating and only parts of the population had to be relocated to refugee camps. Thirty-six children from Kosgoda who were not yet attending school were selected from a refugee camp (all children present that day in this camp) and an additional 72 children were selected from a third- and a seventh-grade school class of a local affected school. In Galle 85 children were selected from a third- and a seventh-grade school class that had already been provisionally reinstated; 41 of them were living in refugee camps. An average of $20 \%$ of children were missing in the school classes in Galle and Kosgoda for reasons that could not be clarified at the time of the interviews. All children who were present the day of the interview could be interviewed. The whole sample included 130 girls and 134 boys; mean age was 11.1 years $(S D=2.0)$.

\section{Instruments}

Posttraumatic stress disorder. The University of California at Los Angeles (UCLA) PTSD Reaction Index (PTSD-RI) for children was used as the main instrument for the assessment of PTSD symptoms. The PTSD-RI is probably the most widely used PTSD instrument for children and adolescents, has proven good psychometric properties, and has been used in a wide variety of cultural settings (for a review see Steinberg, Brymer, Decker, \& Pynoos, 2004). In a previous study (Elbert et al., 2006) this instrument had been translated into Tamil by following standard principles of instrument translation. Rather than relying on a cutoff criterion, we established the diagnosis of PTSD according to the fulfilment of the DSM-IV criteria assessed through the corresponding items (see also La Greca, Silverman, Vernberg, \& Prinstein, 1996). For this purpose, we added five items related to problems in functioning in different areas of children's life. A previous validation study showed a high agreement in the PTSD diagnosis (79\%) between the PTSD-RI as administered by the counselors and expert interviews (Elbert et al., 2006). A Sinhalese translation of the instrument was constructed by following the same principles as part of the training of the Sinhalese-speaking counselors.

Objective tsunami exposure. Four items related to the tsunami experience were added to the instrument (see Table 1). The four questions were answered yes or no. The score for objective tsunami exposure was the number of yes answers. In addition, the children were asked whether they had lost their father or mother in the tsunami and asked about the number of their siblings who had died through this event. The score for family loss was calculated as the number of core family members lost in the tsunami.

Subjective event experience. The PTSD-RI contains 10 items related to the subjective features of the worst traumatic event (e.g., Did you feel that what you saw was disgusting or gross? and Did you feel very confused?). The subjective event experience score was calculated as the sum of yes responses to these items.

Previous traumatic exposure. The score for previous traumatic exposure was calculated as the sum of yes responses to the non-tsunami-related items of the PTSD-RI event checklist (see Table 1).

\section{Data Analusis}

Data were analyzed by using JMP 5.0 (SAS Institute) and $R$ 2.0.1 ( $R$ Development Core Team, Vienna, Austria), including the survey package that allows the calculation of linear models with standard errors corrected for cluster sampling. 
Table 1. Proportions of Children Who Reported Tsunami- and Non-Tsunami-Related Events by Location

\begin{tabular}{lccc}
\hline Experience & Manadkadu $(n=71)$ & Galle $(n=85)$ & Kosgoda $(n=108)$ \\
\hline Objective tsunami features (\%) & & & \\
Fled from wave & 92.9 & 66.3 & 73.1 \\
Saw wave & 85.7 & 63.0 & 57.0 \\
Saw people struggling for life & 71.8 & 59.0 & 45.4 \\
Caught by wave & 41.4 & 35.7 & 16.0 \\
Currently in camp & 100 & 47.7 & 31.4 \\
Lost father & 2.8 & 7.1 & 1.9 \\
Lost mother & 4.3 & 9.4 & 1.9 \\
Lost one sibling & 12.7 & 13.3 & 8.6 \\
Lost two siblings & 5.6 & 3.6 & 0 \\
Lost three or more siblings & 7.0 & 1.2 & 0 \\
Previous traumatic events (\%) & & & \\
War experiences & 59.1 & 4.8 & 4.7 \\
Witnessing of physical violence at home & 16.9 & 23.8 & 16.8 \\
Serious medical treatment & 18.3 & 33.3 & 23.2 \\
Earthquake & 8.8 & 2.3 & 1.8 \\
Experiencing of physical abuse at home & 11.4 & 27.0 & 15.0 \\
Serious physical attack or threat & 5.7 & 9.4 & 9.3 \\
Witnessing of beating or killing & 35.2 & 25.3 & 29.2 \\
Severe accident & 2.8 & 46.0 & 42.0 \\
Sexual abuse & 1.4 & 4.7 & 0.9 \\
Any previous traumatic event & 91.6 & 88.2 & 81.5 \\
\hline
\end{tabular}

Table 2. Trauma Exposure Scores by Location

\begin{tabular}{lcccc}
\hline & Manadkadu $(n=71)$ & Galle $(n=85)$ & Kosgoda $(n=108)$ & \\
Event scores & $M(S D)$ & $M(S D)$ & $M(S D)$ & $F(2,261)$ \\
\hline Objective tsunami exposure score & $2.90(1.00)^{\mathrm{a}}$ & $2.18(1.50)^{\mathrm{b}}$ & $1.88(1.32)^{\mathrm{b}}$ & $13.34^{* *}$ \\
Number of family members who died in tsunami & $.52(.98)^{\mathrm{a}}$ & $.40(.80)^{\mathrm{a}}$ & $.12(.43)^{\mathrm{b}}$ & $6.85^{* *}$ \\
Subjective experience score & $6.37(2.93)^{\mathrm{ab}}$ & $6.66(3.19)^{\mathrm{b}}$ & $5.26(3.55)^{\mathrm{a}}$ & $4.84^{* *}$ \\
Previous traumatic exposure score & $2.48(1.64)^{\mathrm{a}}$ & $2.56(1.87)^{\mathrm{a}}$ & $2.06(1.68)^{\mathrm{a}}$ & 2.31 \\
\hline
\end{tabular}

Note. Values with indices were analyzed for differences between locations: levels not connected by the same letter were significantly different in a pairwise comparison (Tukey test after analysis of variance, $p<.05$ ).

${ }^{* *} p<.01$.

\section{RESULTS}

\section{Independent Variables by Location}

Table 1 shows the prevalence of traumatic tsunami-related events, the subjective reactions to the worst traumatic event, as well as the traumatic events before the tsunami, divided by the three locations. The scores for objective tsunami exposure, subjective event experience, family loss, and previous traumatic exposure were compared for the locations (see Table 2).

The analysis of the PTSD data revealed that the majority of children $(n=241)$ could report an event that fulfilled the A1 criterion for traumatic event according to the DSM-IV. For the majority of children $(n=171)$, the worst event was related to the tsunami. The most common 
Table 3. Percentage of Children Who Fulfilled DSM-IV Criteria for PTSD by Location and Type of Worst Event

\begin{tabular}{lcccccccc}
\hline & \multicolumn{3}{c}{ Tsunami } & & \multicolumn{3}{c}{ Other traumatic event } \\
\cline { 2 - 3 } PTSD criterion (\%) & $\begin{array}{c}\text { Manadkadu } \\
(n=53)\end{array}$ & $\begin{array}{c}\text { Galle } \\
(n=64)\end{array}$ & $\begin{array}{c}\text { Kosgoda } \\
(n=56)\end{array}$ & & $\begin{array}{c}\text { Manadkadu } \\
(n=16)\end{array}$ & $\begin{array}{c}\text { Galle } \\
(n=13)\end{array}$ & $\begin{array}{c}\text { Kosgoda } \\
(n=39)\end{array}$ \\
\hline A2 (Subjective event criterion) & 98.1 & 98.4 & 94.7 & & 62.5 & 92.3 & 66.7 \\
B (Intrusion) & 96.2 & 93.8 & 94.7 & & 68.8 & 92.3 & 74.4 \\
C (Avoidance) & 54.7 & 68.8 & 46.4 & & 56.2 & 53.8 & 41.0 \\
D (Hyperarousal) & 90.6 & 87.5 & 85.7 & & 81.2 & 61.5 & 64.1 \\
F (Functioning) & 75.5 & 70.3 & 44.6 & & 56.2 & 53.9 & 41.0 \\
PTSD & 45.3 & 51.6 & 26.8 & & 37.5 & 38.5 & 12.8 \\
\hline
\end{tabular}

Note. PTSD = posttraumatic stress disorder. Table excludes 23 children who did not report any traumatic event; tsunami-related PTSD criteria exclude the time criterion.

non-tsunami-related worst events were seeing a dead body $(n=14)$, hearing about the violent death or serious injury of a loved person $(n=12)$, witnessing severe violence in town $(n=10)$, having painful and scary medical treatment in a hospital $(n=9)$, witnessing domestic violence $(n=5)$, and being at a war place $(n=4)$.

Table 3 presents the prevalence rates of the DSMIV PTSD criteria according to the type of worst event (tsunami vs. previous traumatic event) and location. The criteria do not allow diagnosis of PTSD within 4 weeks of the traumatic event. Consequently, the diagnosis of tsunami-related PTSD was still tentative although a preliminary PTSD diagnosis including all criteria except the time criterion is a strong predictor for the development of chronic PTSD in children (Meiser-Stedman et al., 2005). According to the PTSD-RI, $8.5 \%$ of the examined children in Manadkadu, $5.9 \%$ of the children in Galle, and $4.6 \%$ of the children interviewed in Kosgoda fulfilled PTSD criteria related to a previous traumatic event. An additional 33.8\% in Manadkadu, 38.8\% in Galle, and $13.9 \%$ in Kosgoda fulfilled all DSM-IV criteria for PTSD related to tsunami experiences, except the time criterion. A pairwise comparison of the overall PTSD rates in the locations revealed no significant difference between Manadkadu and Galle, $\chi^{2}(1, N=156)$ $<1$. Kosgoda presented the lowest PTSD rate compared to both Manadkadu, $\chi^{2}(1, N=197)=11.98, p<.001$, and Galle, $\chi^{2}(1, N=193)=15.58, p<.001$.

\section{Intercorrelations of Independent Variables}

Subjective event experience and objective tsunami exposure correlated with each other, $r=.57, p<.001$, and with the number of family members who died in the tsunami, $r=.20$ and .26 , respectively, both $p<.01$. Subjective experience also depended on previous traumatic experience, $r=.40, p<.001$. Age correlated positively with objective exposure and subjective experience as well as with previous traumatic exposure, $.22 \leq r \leq .35$; all $p<.001$. Gender did not correlate significantly with any of the other independent variables.

\section{Prediction of PTSD S4mptoms}

To examine potential predictors for the presence of posttraumatic symptoms in general, as well as the development of posttraumatic symptoms after the tsunami, we calculated correlations and linear regression models separately for the whole group and for those who reported the tsunami as their worst event. The PTSD-RI sumscore was used as a dependent variable. Results of the analysis are presented in Table 4. The main predictors of both tsunamirelated and non-tsunami-related posttraumatic symptoms were the subjective aversive experiences during the worst event, the objective severity of the exposure to the tsunami, the number of family members who died in the tsunami, as well as the number of traumatic events experienced 
Table 4. Relationship Between Predictor Variables and the Severity of Posttraumatic Symptoms by Type of Worst Event

\begin{tabular}{|c|c|c|c|c|}
\hline \multirow[b]{2}{*}{ Predictor } & \multicolumn{2}{|c|}{ All traumatic events $(n=264)$} & \multicolumn{2}{|c|}{ Tsunami $(n=173)$} \\
\hline & Zero-order correlation & $\beta$ & Zero-order correlation & $\beta$ \\
\hline Age & $.20^{* *}$ & -.02 & .09 & -.05 \\
\hline Gender (female) & .01 & .02 & .05 & -.02 \\
\hline Previous traumatic exposure & $.42^{* * *}$ & $.17^{* *}$ & $.38^{* * *}$ & $.21^{* *}$ \\
\hline Number of family members who died in tsunami & $.20^{* * *}$ & $.15^{* *}$ & $.19^{* *}$ & $.13^{*}$ \\
\hline Objective tsunami experience & $.39^{* * *}$ & .01 & $.23^{* *}$ & .01 \\
\hline Subjective event experience & $.59^{* * *}$ & $.48^{* * *}$ & $.48^{* * *}$ & $.39^{* * *}$ \\
\hline
\end{tabular}

Note. Zero-order correlation is represented by Spearman's rho for continuous predictor variables and point-biserial correlation for dichotomous predictor variables; $\beta$ coefficients are standardized and result from a linear regression model of PTSD severity; full models adjusted $R^{2}=.34$ for the whole group and $R^{2}=.24$ for those who reported the tsunami as worst event.

${ }^{*} p<.05 .{ }^{* *} p<.01 .{ }^{* * *} p<.001$.

before the tsunami. In a regression analysis, age and gender did not predict posttraumatic stress symptoms. In addition, objective traumatic exposure did not explain posttraumatic stress independently of the other predictors.

\section{DISCUSSION}

At 3 to 4 weeks after the tsunami disaster we examined PTSD in children living in three severely affected communities. Across all communities, $87 \%$ of the children reported one or more traumatic events before the tsunami. Previous traumatic exposure was high in the Tamil region, which had been affected by the civil war, as well as in the Sinhalese regions that had been peaceful in recent years. Depending on location, between $4.6 \%$ and $8.5 \%$ of children had PTSD unrelated to the tsunami. An additional $13.9 \%$ to $38.8 \%$ of children fulfilled the preliminary diagnosis of tsunami-related PTSD.

Posttraumatic stress symptoms were mainly predicted by variables comprising the severity of traumatic exposure including the loss of family members, both for all events and for the tsunami. In a regression analysis, the objective severity of the tsunami experience lost its impact because it was highly correlated with the subjective experience that mediated the effect of the objective features. It is noteworthy that the influence of previous traumatic exposure and tsunami exposure was almost equivalent for the calculation including all traumatic events and the analysis restricted to tsunami stress. This finding suggests that the life-threatening tsunami experience may have caused an aggravation of symptoms related to previous experiences. At the same time, the previously experienced traumatic events have probably increased the vulnerability for posttraumatic symptoms related to the tsunami. The finding that previous traumatic exposure is a significant predictor for the development of disaster-related PTSD supports a general dose-effect model of PTSD (Neuner et al., 2004) and might help to explain why PTSD rates after disaster are higher in developing countries, which are often characterized by high levels of violence.

Although we could not achieve a representative sampling of children soon after the tsunami, the study indicates that PTSD is a highly prevalent mental health problem for children living in the affected areas in Sri Lanka. There is no reliable information about the rate of spontaneous recovery from high initial rates of PTSD in children. Meiser-Stedman and colleagues (2005) found that the PTSD rate among children in a London emergency department dropped by 50\% from an assessment in the first month to a 6-month follow-up. After Hurricane Andrew in Florida, La Greca and colleagues (1996) observed a reduction in PTSD prevalence from 39\% 3 months after the event to $18 \%$ at 10 months after the event among affected children. This reduction in PTSD cases might overestimate the spontaneous recovery from PTSD symptoms in this study as the mean PTSD-RI score 
only dropped by about half a standard deviation in this period. Unfortunately there is no longitudinal study that observed the recovery rates of child victims in developing countries. For adults, Norris, Murphy, Baker, and Perilla (2004) showed that the PTSD prevalence among adults affected by the 1999 flood in Mexico dropped by approximately $50 \%$ in the first 18 months after the event. From this time point, the symptoms seemed to stabilize as no further recovery could be observed between 18 and 24 months post disaster. These findings from longitudinal studies do not allow a precise prediction of the development of PTSD in children. Taking the high level of previous traumatic experiences into account, a high rate of long-lasting and chronic PTSD can be expected in Sri Lankan children who experienced the tsunami.

Longitudinal studies of children in developing countries are urgently needed to estimate recovery rates and to identify predictors of adverse development. The fact that recovery rates among children seem to be limited even in industrial countries and the evidence for stabilization point to the need for adequate mental health assistance. The traumatized children in Sri Lanka have a right to evidence-based treatment. Unfortunately there is a lack of treatment research about traumatized children in developing countries, although pragmatic interventions for children and adolescents in developing countries have been developed (Onyut et al., 2005; Saltzman, Layne, Steinberg, Arslanagic, \& Pynoos, 2003) and pilot evaluation studies suggest the feasibility and efficacy of specialized treatment approaches based on scientific knowledge (Goenjian et al., 1997). Randomized trials are urgently necessary to identify feasible and effective procedures in field conditions in developing countries, before ad hoc interventions of questionable efficacy are implemented in large-scale psychosocial programs.

\section{REFERENCES}

American Psychiatric Association (1994). Diagnostic and statistical manual of mental disorders (4th ed.). Washington, DC: Author.

Bremner, J. D., Southwick, S. M., Johnson, D. R., Yehuda, R., \& Charney, D. S. (1993). Childhood physical abuse and combat-related posttraumatic stress disorder in Vietnam veterans. American Journal of Psychiatry, 150, 235239.

Catani, C., Schauer, E., Onyut, L. P., Schneider, C., Neuner, F., Hirth, M., et al. (2005). Prevalence of PTSD and building-block effect in school children of Sri Lanka's north-eastern conflict areas. Paper presented at the Ninth European Conference on Traumatic Stress Studies, Stockholm, Sweden.

Elbert, T., Huschka, B., Schauer, E., Schauer, M., Hirth, M., Rockstroh, B., et al. (2006). Trauma-related impairment in children-An epidemiological survey in Sri Lankan provinces affected by two decades of civil war and unrest. Manuscript submitted for publication.

Goenjian, A. K., Karayan, I., Pynoos, R. S., Minassian, D., Najarian, L. M., Steinberg, A. M., et al. (1997). Outcome of psychotherapy among early adolescents after trauma. American Journal of Psychiatry, 154, 536-542.

Goenjian, A. K., Molina, L., Steinberg, A. M., Fairbanks, L. A., Alvarez, M. L., Goenjian, H. A., et al. (2001). Posttraumatic stress and depressive reactions among Nicaraguan adolescents after Hurricane Mitch. American Journal of Psychiatry, 158, 788794.

Goenjian, A. K., Najarian, L. M., Pynoos, R. S., Steinberg, A. M., Petrosian, P., Setrakyan, S., et al. (1994). Posttraumatic stress reactions after single and double trauma. Acta Psychiatrica Scandinavia, 90, 214-221.

Goenjian, A. K., Pynoos, R. S., Steinberg, A. M., Najarian, L. M., Asarnow, J. R., Karayan, I., et al. (1995). Psychiatric comorbidity in children after the 1988 earthquake in Armenia. Journal of the American Academy of Child and Adolescent Psychiatry, 34, 1174-1184.

Goenjian, A. K., Steinberg, A. M., Najarian, L. M., Fairbanks, L. A., Tashjian, M., \& Pynoos, R.S. (2000). Prospective study of posttraumatic stress, anxiety, and depressive reactions after earthquake and political violence. American Journal of Psychiatry, 157, 911-916.

International Federation of Red Cross and Red Crescent Societies. (2004). World disasters report 2004. Geneva: Author.

La Greca, A., Silverman, W. K., Vernberg, E. M., \& Prinstein, M. J. (1996). Symptoms of posttraumatic stress in children after Hurricane Andrew: A prospective study. Journal of Consulting and Clinical Psychology, 64, 712-723.

Meiser-Stedman, R., Yule, W., Smith, P., Glucksman, E., \& Dalgleish, T. (2005). Acute stress disorder and posttraumatic stress disorder in children and adolescents involved in assaults or motor vehicle accidents. American Journal of Psychiatry, 162, 1381-1383. 
Neuner, F., Schauer, M., Karunakara, U., Klaschik, C., Robert, C., \& Elbert, T. (2004). Psychological trauma and evidence for enhanced vulnerability for posttraumatic stress disorder through previous trauma among West Nile refugees. BMC Psychiatry, 4, 34.

Norris, F. H., Friedman, M. J., Watson, P. J., Byrne, C. M., Diaz, E., \& Kaniasty, K. (2002). 60,000 disaster victims speak: Part 1. An empirical review of the empirical literature, 1981-2001. Psychiatry, 65, 207-239.

Norris, F. H., Murphy, A. D., Baker, C. K., \& Perilla, J. L. (2004). Postdisaster PTSD over four waves of a panel study of Mexico's 1999 flood. Journal of Traumatic Stress, 17, 283292.

Onyut, L. P., Neuner, F., Schauer, E., Ertl, V., Odenwald, M., Schauer, M., et al. (2005). Narrative exposure therapy as a treatment for child war survivors with posttraumatic stress disorder: Two case reports and a pilot study in an African refugee settlement. BMC Psychiatry, 5, 7.
Saltzman, W. R., Layne, C. M., Steinberg, A. M., Arslanagic, B., \& Pynoos, R.S. (2003). Developing a culturally and ecologically sound intervention program for youth exposed to war and terrorism. Child and Adolescent Psychiatric Clinics of North America, 12, 319-342.

Scott, R. L., Knoth, R. L., Beltran-Quiones, M., \& Gomez, N. (2003). Assessment of psychological functioning in adolescent earthquake victims in Colombia using the MMPI-A. Journal of Traumatic Stress, 16, 49-57.

Somasundaram, D. (1993). Child trauma. Jaffna, Sri Lanka: University of Jaffna.

Steinberg, A. M., Brymer, M. J., Decker, K. B., \& Pynoos, R. S. (2004). The University of California at Los Angeles Posttraumatic Stress Disorder Reaction Index. Current Psychiatry Reports, 6, 96-100.

World Health Organization. (2004). International statistical classification of diseases and health related problems ICD-10 (2nd ed.). Geneva, Switzerland: Author. 